\title{
Capital Cost Estimation for Advanced Nuclear Power Plants
}

\author{
Stewart W.B. ${ }^{1}$, Shirvan K. ${ }^{1, *}$ \\ ${ }^{1}$ Department of Nuclear Science and Engineering, Massachusetts Institute of Technology, USA \\ * Corresponding Author. Email Address: kshirvan@mit.edu (K. Shirvan)
}

\section{Abstract}

The first-of-a-kind (FOAK) nuclear plants built in the last 20 years are $2 X$ over budget and schedule in the US and some European countries. One of the nuclear industry's proposed remedies is the small modular reactor (SMR). SMR designs leverage five factors to be more economically competitive than large reactors: 1) multiple units; 2) increased factory production and learning; 3 ) reduced construction schedules; 4) plant design simplification and 5) unit timing. There are currently no studies that quantitatively account for these factors and compare different near term SMRs with Gen III+ large plants. This work presents a nuclear plant cost estimating methodology using a detailed bottom up approach for over 200 structures, systems, and components. The results compare relative cost for two large pressurized water reactors, one with active safety and one with passive safety, to two SMR designs, one with multiple reactor power modules and one with a single reactor module. Passive safety systems showed noticeable savings at both the large and small scale reactors. The power uprating of a SMR by $20 \%$ resulted in $~ 15 \%$ savings in the overnight unit capital cost. Overall, if built by an inexperience vendor and work force, the two SMRs' overnight cost were higher than large reactors since significant on-site labor still remains while losing economy of scale. However, the single-unit SMR had significantly less total person-hours of onsite labor, and if built by an experienced workforce, its overnight construction cost showed potential to be competitive and avoid cost-overrun risks associated with megaprojects.

\section{Highlights:}

- Bottom-up cost estimation of large and small nuclear plants are made.

- Typical SMRs require at least similar unit on-site labor hours vs. large reactors.

- Introduction of passive safety and power uprate are effective at reducing cost.

- FOAK overnight unit cost of SMRs can be noticeably higher than large reactors.

- Experienced vendor and work force could make SMRs competitive with large plants.

Keywords: Nuclear Energy, Cost Estimation, SMR, Megaprojects, Modular Construction

Word Count: 7,701

\section{List of Abbreviation}

BE - Best Experience

EEDB - Economic Energy Data Base

FOAK - First-Of-A-Kind

I'S-LWR - Integral Inherently Safe Light Water Reactor

IAEA - International Atomic Energy Agency

iPWR - Integral PWR 
kWe - Kilo-Watts Electric

LASR - Large Active Safety Reactor

LPSR - Large Passive Safety Reactor

ME - Median Experience

MIT - Massachusetts Institute of Technology

MMNC - Multi-module Natural Circulation

MWe - Mega-Watts Electric

NC-SMR - Natural circulation SMR

NOAK - Nth-Of-A-Kind

NSSS - Nuclear Steam Supply System

O\&M - Operation and Maintenance

PWR - Pressurized Water Reactor

PWR12 - Westinghouse Pressurized Water Reactor

RMS - Root Mean Square

ROK - Republic Of Korea

RPV - Reactor Pressure Vessel

SMR - Small Modular Reactor

SSCs - Structures Systems and Components

\section{Introduction}

Cost has been the primary issue facing the nuclear industry for over twenty years. When explaining the relatively limited expansion of nuclear power, the recent MIT Future of Nuclear report stated, "the fundamental problem is cost" [1]. An assessment by the Nuclear Energy Agency of FOAK nuclear plants that began construction in the last fifteen years showed an average cost escalation and construction delays of $2 X$ the original estimate [2]. Lovering et al. showed that many countries experienced reductions in specific capital costs in their early days of adoption through the economy of scale [3]. More recently, however, on average large nuclear plants have become untenable megaprojects suffering from mismanagement and overly complex designs. The notable exceptions to this experience were the first four Advanced Boiling Water Reactors built in Japan in the 1990s and 2000s which were all completed in under four years and under-budget.

The proposed remedy is the small modular reactor (SMR) which aims to simplify and standardize nuclear plants away from the megaproject scale seen today. Carelli et al. outlined a set of six factors for estimating the cost competitiveness of SMRs: economy of scale, multiple units, learning, construction schedule, unit timing, and plant design [4]. The loss of economy of scale escalates specific capital costs for SMRs, but the other five factors may make up the difference. Kuznetsov pointed to similar factors: reducing complexity, sizing the reactor for transportability, off-site refueling, multi-module sites, and higher thermal efficiencies [5]. However, some studies question the cost reduction potential [6] and technological advantages of SMRs [7].

Moreover, it is not trivial to quantify the magnitude of these factors for a specific nuclear plant design. Carelli et al. estimated the value of their six factors for a four pack of the 335 MWe IRIS reactor concept: economy of scale -1.7 , multiple units -0.86 , learning curve -0.92 , construction schedule $\&$ timing 0.94 cumulative, and plant design - 0.83 [4]. In net, the generic SMR had a $5 \%$ higher capital cost than a generic large reactor. Meanwhile, in the recent International Atomic Energy Agency (IAEA) handbook, 
SMART SMR was listed at $\$ 10,000 / \mathrm{kWe}, 4 x$ higher than the experience of APR1400 in Republic of Korea (ROK) [8]. SMART, however, has only 100 MWe of capacity, so it pays a higher economy of scale penalty than other SMR designs.

In this study, we reframed the six factors from Carelli et al. Modularization was separated from plant design, as it is something that can be applied to systems within a plant design. Unit timing was rolled into construction schedule, as also done by Carelli et al., because it is the shortened construction schedule that allows for units to be delivered on pace with demand growth. The multiple unit factor was folded into the plant design because some designs are multi-unit by design such as NuScale. Finally, megaproject risk was added because it is a significant cost barrier for the industry today. Table 1 summarizes these factors, their components, and their impact as used in this study. These factors are all highly correlated - they each can impact the cost of the same structure, system, or component in different ways. This creates a challenge when trying to generalize their impact across multiple SMR designs and highlights the need for a case-by-case quantification.

Table 1. Factors driving cost, the components used to estimate them, and how each factor impacts cost or value. *Construction schedule was not considered as part of this study.

\begin{tabular}{|l|l|l|}
\hline Cost Factor & Components & Impact and Value \\
\hline Economy of scale & Structures, components, labor & Baseline cost \\
\hline Learning & Factory, site labor, and site material learning rates & Future cost \\
\hline Modularization & $\begin{array}{l}\text { Cost of building a factory, percentage of work moved } \\
\text { offsite, offsite labor efficiency gain }\end{array}$ & $\begin{array}{l}\text { Baseline cost, Construction } \\
\text { schedule }\end{array}$ \\
\hline Plant design & $\begin{array}{l}\text { Active/passive safety, plant simplification (e.g. integral } \\
\text { PWR), new architectures (submerged containment } \\
\text { vessel) }\end{array}$ & Baseline cost \\
\hline Construction schedule* & $\begin{array}{l}\text { Overnight cost, construction method (e.g. steel plate } \\
\text { composites), total site labor hours, offsite work, } \\
\text { regulatory risk }\end{array}$ & Cost and schedule overrun \\
\hline Economy of scale, modularization, plant design, learning & $\begin{array}{l}\text { Interest during construction, } \\
\text { capital at risk }\end{array}$ \\
\hline
\end{tabular}

Mignacca et al., in a review of SMR economics, noted that "there is a lack of standardized approach in the evaluation and economic performance of SMRs" [9]. There are several design specific cost estimates but their methodologies vary. An AP1000 estimate by Black \& Veatch was a point estimate, not a detailed assessment of the structures, systems, and components[10]. A NuScale estimate by Scherrer was closed and confidential [11], and an estimate by Black et al. cited proprietary vendor data [12] UxC reported vendor cost estimates from NuScale, mPower, SMR-160 [13]. Zhang et al. showed that a twounit high temperature gas reactor SMR had a $5 \%$ higher cost than a single unit with a larger power capacity due to plant simplicity and economy of multiples [15]. Maronati et al. estimated the cost of a large reactor, the Integral Inherently Safe Light Water Reactor (I'2S-LWR) using cost data based on a 1144 MWe pressurized water reactor in the Economic Energy Data Base (EEDB) [16]. They used commodity quantities and design-specific details to scale the costs from the EEDB to I'S-LWR, and they expanded the EEDB to account for new technology such as micro-channel heat exchangers and seismic isolation. Most recently, Lloyd et al. conducted a study of nuclear costs showing that a high degree of modularization could reduce capital costs for a 300 MWe SMR 45\%, giving it a lower cost than a large reactor [17]. 
The IAEA and Ganda et al. each published a methodology for nuclear plant cost estimation. The IAEA feature cost scaling method uses nine plant design characteristics, such as thermal power, efficiency, power density, number of fuel elements, etc., to estimate the capital cost [18]. However, this method cannot estimate the cost of unconventional designs such as the NuScale's containment vessel, so it is limited to designs similar to the reference plant. Similar to Maronati et al., Ganda et al. estimated the cost of the ABR1000 sodium cooled reactor by scaling reference nuclear plant cost data from the EEDB [19] using over 30 design features including volumes and surface area of structures, primary pump flow rates, pressure vessel mass, waste production rates and others [20]. Ganda et al. included labor and material cost uncertainty in an update to their method [21]. Neither model estimates the impact of learning rates, modularization, or indirect costs. The OPEN100 estimated the cost of their open-source 100 MWe PWR by linearly scaling the highest level EEDB costs and applying cost reductions from other industries [22]. Champlin estimated the cost of applying advanced construction techniques such as steel plate composites to containments and shield buildings [23].

In this work, we present a nuclear capital cost estimation methodology that is based on the EEDB [19], is applicable to all light water reactor designs, and establishes a consistent set of assumptions to quantify deriving cost factors for the selected designs. Then, we use the tool to estimate the capital costs of large LWRs, based on publicly available information for AP1000 and APR1400 and small modular reactors, based on public information available for NuScale and SMR-160 plant designs. This work distinguishes itself from its predecessors in its detailed bottom-up approach using best engineering based judgment and practices to capture the intrinsic features of SMR designs, including factory production, learning rates, passive safety, simplified electrical and piping while quantifying the lack of economy of scale in a holistic framework.

\section{Methodology}

Using assumed component cost scaling relationships collected from a range of sources [21] [24] [25], we use the EEDB as a baseline to estimate costs. The EEDB is a detailed, component-by-component cost breakdown of over 1400 cost items for a four loop $1200 \mathrm{MWe}$ Westinghouse pressurized water reactor (PWR12). For each cost item, the EEDB provided the factory cost, site labor cost, site labor hours, material quantity, and material cost. Costs are organized into a code of accounts system, with one-digit accounts summing their respective two-digit accounts and so forth up to ten digits of detail. Table 3 is a summary of the one- and two-digit accounts. The database contains costs for median experience plant builds (PWR12-ME) and better experience plant builds (PWR12-BE), and the PWR12-ME capital cost was more than double the PWR12-BE capital cost. In this analysis, the PWR12-ME was taken to be representative of FOAK cost, and therefore, the FOAK estimates in this study include an implicit contingency (defined narrowly as allocated risk in the predicted overnight construction cost) based on the median experience plants built. In this way, contingency costs were distributed across the relevant cost accounts as indicated by the difference between the PWR12-BE and PWR12-ME three-digit accounts. This is an important note as typical publicly published cost data by vendors are NOAK cost estimates. In the following sections we present: methods for inflating the EEDB from 1987 to 2018 for scaling each component cost, for accounting for modularization and learning to reach NOAK cost, for design specific adjustments, and for estimating indirect costs.

The EEDB combined all the factory nuclear steam supply system (NSSS) costs into a single account, 220. This account included the costs of the reactor pressure vessel, steam generator, primary coolant piping, 
pressurizer, and control rods. Ganda performed an extensive cost analysis dividing the single factory costs among these specific components [20]. This work adopted Ganda's breakdown of NSSS factory costs.

To bound the range of SSCs necessary to model within the cost tool, this study analyzed four different nuclear plant designs beyond PWR12. The first was a large (>1000 MWe) Gen III+ PWR with passive safety systems similar to the Westinghouse AP1000 design. The second was a large Gen III+ PWR with active safety systems similar to the KEPCO APR1400. The third was a multi-module, small modular, natural circulation, integral PWR similar to NuScale. The fourth was small modular, natural circulation, integral PWR similar to the Holtec SMR-160. It should be noted that the Holtec SMR-160 design is the only one that has not gone through design certification and its design specifications will likely evolve more relative to the other reference designs.

Table 2. This study considered four nuclear plants beyond PWR12: a Gen III+ passively safe PWR - LPSR, a Gen III+ actively safe PWR LASR, a multi-module small modular reactor - MMNC, and a single module small modular reactor - NC-SMR.

\begin{tabular}{|l|c|l|l|c|c|}
\hline Name: & PWR12 & $\begin{array}{l}\text { Large Passive } \\
\text { Safety PWR } \\
\text { (LPSR) }\end{array}$ & $\begin{array}{l}\text { Large Active } \\
\text { Safety PWR } \\
\text { (LASR) }\end{array}$ & $\begin{array}{l}\text { Multi-module } \\
\text { Natural Circulation } \\
\text { iPWR (MMNC) }\end{array}$ & $\begin{array}{l}\text { Natural } \\
\text { circulation SMR } \\
\text { (NC-SMR) }\end{array}$ \\
\hline Similar to: & $\begin{array}{c}\text { Westinghouse 4- } \\
\text { Loop PWR }\end{array}$ & $\begin{array}{l}\text { Westinghouse } \\
\text { AP1000 }\end{array}$ & KEPCO APR1400 & NuScale & $\begin{array}{l}\text { Holtec } \\
\text { SMR-160 }\end{array}$ \\
\hline Net Power (MWe) & 1144 & 1117 & 1400 & $12 \times 57^{*}(685$ total) & 160 \\
\hline
\end{tabular}

*Note in section 3.3 we will explore the recently announced $77 \mathrm{MWe}$ reactor module

The methodology of our model was a six-step process graphically explained in Figure 1. The EEDB was reduced to 204 SSCs known to be cost drivers and design differentiators. The cost estimation tool: 1) scaled each cost based on the details of the plant, 2) made adjustments for novel components, 3) reduced costs for known simplifications, 4) modularized the applicable SSCs, 5) applied learning rates, and 6) estimated the indirect costs.

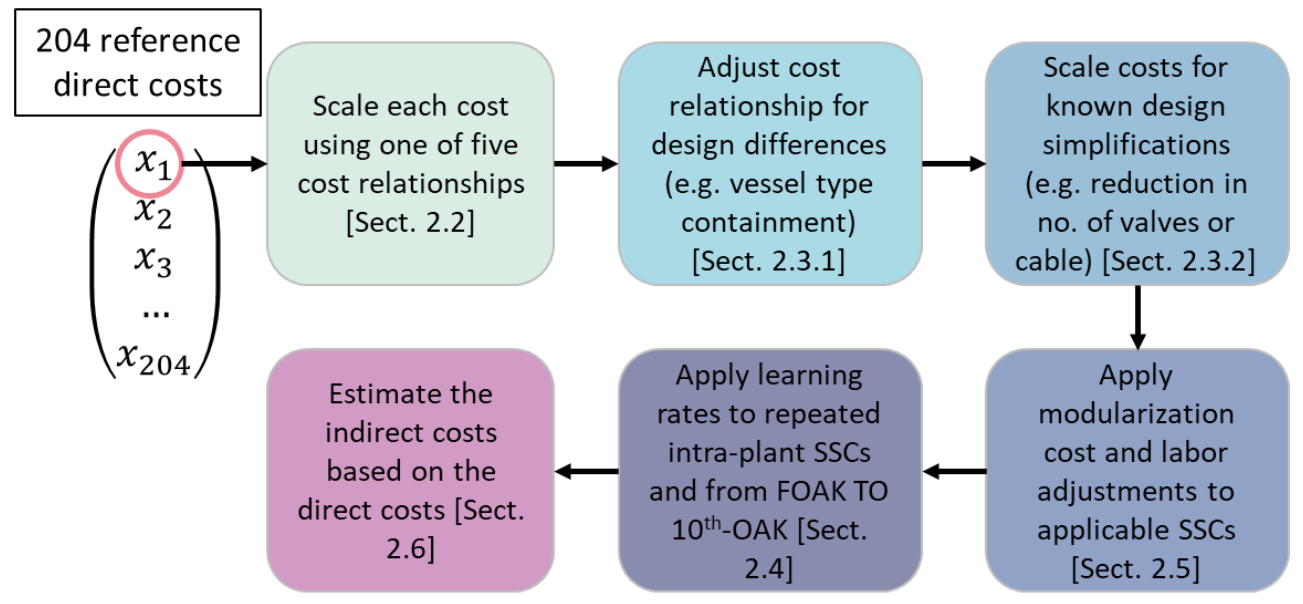

Figure 1. Graphical representation of the steps in the cost estimation process and the corresponding section of the article that discusses the details behind the step.

\subsection{Inflation and cost escalation}

The DOE published the most recent version of the EEDB in 1987, so the factory, labor, and material costs need to be inflated and escalated to the 2018 cost basis chosen for this work. Each labor and material cost were inflated using the appropriate index from the Bureau of Labor Statistics [26]. For example, the 
pipe fitter index applied to labor costs for piping, the millwright index applied to labor costs for equipment installation, the wire and cable index applied to material costs for electrical work, etc. Factory costs were escalated with the most similar material cost index. This approach properly accounted for varying inflation rates and avoided the five year limit on inflating heavy industry plant costs [27].

Above inflation, Ganda et al. and the Electric Power Research Institute applied nuclear escalation rates of $30 \%$ and $70 \%$ respectively [20] [28]. The nuclear escalation rates account for changes in regulation and losses in nuclear project construction management expertise. These escalation rates applied uniformly to all capital costs, so we did not apply them in this work. Therefore, given other uncertainties, the results in this study should be considered relative to one another and not in an absolute sense. Actual costs of a future project may vary with changes to environmental factors left unquantified here.

Regulation may change and either increase or reduce actual project cost of a FOAK plant. The location of a project has a similar effect, as the environmental factors differ among countries. Table 3 provides the one- and two-digit account summary results for this inflation. It should be noted that the assumed inflation is only applicable to US project cost estimates.

Table 3. One- and two-digit accounts for the PWR12-ME inflated to 2018 (\$/kWe)

\begin{tabular}{|l|l|r|r|r|r|}
\hline Account & Account Description & Factory Cost & Labor Cost & Material Cost & Total Cost \\
\hline A.1 & Total Base Cost & 2,760 & 1,349 & 591 & 4,700 \\
\hline A.2 & Total Direct Costs & 997 & 1,006 & 295 & 2,299 \\
\hline A.21 & Structures and Improvements & 45 & 391 & 176 & 612 \\
\hline A.22 & Reactor Plant Equipment & 440 & 204 & 38 & 682 \\
\hline A.23 & Turbine Plant Equipment & 348 & 148 & 22 & 519 \\
\hline A.24 & Electric Plant Equipment & 63 & 131 & 38 & 233 \\
\hline A.25 & Miscellaneous Plant Equipment & 39 & 86 & 13 & 138 \\
\hline A.26 & Main Condenser Heat Reject System & 61 & 46 & 8 & 115 \\
\hline A.9 & Total Indirect Costs & 1,763 & 343 & 296 & 2,402 \\
\hline A.91 & Construction Services & 203 & 306 & 258 & 766 \\
\hline A.92 & Engineering \& Home Office Service & 841 & 0 & 0 & 841 \\
\hline A.93 & Field Supervision \& Field Office Service & 719 & 38 & 38 & 794 \\
\hline
\end{tabular}

\subsection{Direct cost estimation methods}

The developed cost estimate tool utilizes five methods for scaling and estimating 204 separate direct SSC costs from the EEDB PWR12-ME for a new plant. A full list of these costs can be found in the supplementary information, the scaling method used, and the parameter values can be found in the supplementary information. As an indication of the level of detail, the median value of these 204 SSC costs was $\$ 1.6 \mathrm{M}$ for PWR12-ME. This first method came from Towler et al. for systems and equipment costs and follows Equation 1:

\section{Equation 1}

$$
C=A *\left[B+D * P^{n}\right]
$$

Where $C$ is the cost; $A$ is the nuclear cost escalation factor; $B, D$, and $n$ are constants from Towler et al. inflated to 2018 using the Chemical Engineering Plant Cost Index, and $P$ is a parameter describing the component [24]. This method applied to twelve costs including the reactor pressure vessel (RPV), primary pumps, steam generator, pressurizer, cranes, and the NuScale containment vessel. The parameter, $P$, was either the vessel mass, steam generator heat transfer area, pump flow rate, or crane 
capacity. The nuclear cost escalation factor came from escalating the estimate from Towler to match the reported value for PWR12-ME. The difference between Towler and PWR12-ME ranged from 13-20X.

The second method was applied to 131 SSC costs and used the parameter, $P$, and exponent, $n$, recommended by Towler in an exponentially scaled relationship to the EEDB cost:

\section{Equation 2}

$$
C=C_{E E D B} *\left(\frac{P_{\text {new }}}{P_{E E D B}}\right)^{n}
$$

This comparative method mostly applied to structures and buildings, so the parameter, $P$, was the volume of the foundation, surface area of the containment, or other structures-based values. This method also applied to service air, water, and steam systems that scaled on building volumes, control rod drive systems that scaled on the number of control rods, and waste processing systems that scaled on the primary coolant flow rate.

The third method used Equation 2 but either the plant level thermal or electrical power (in the case of multi-unit sites). 35 SSC costs scaled with this method including turbine equipment, electrical equipment, and the safety grade HVAC systems in the reactor and auxiliary buildings. This method also applied in cases where the SSC parameter was unknown for less developed plant designs. Using the plant level thermal power allowed for cost savings in multi-unit designs like NuScale where several reactors will share systems and equipment.

The fourth method was a fixed cost at the PWR12-ME cost. This applied to costs such as the security building, fire house, technical support center, some monitoring systems, and waste water treatment systems. The final method was simply a direct cost input, so that the users could apply their own known cost. This method was not used in any of the estimates in this study.

\subsection{Design specific adjustments}

\subsubsection{Containments}

The AP1000 has a fundamentally different containment than the PWR12: it uses a standalone steel structure surrounded by a reinforced concrete shield building instead of a steel lined reinforced concrete shell. The EEDB estimated the cost for a standalone steel containment structure for the APWR6, a 600 MWe advanced-PWR, and the cost for a steel lined reinforced concrete shell for the PWR6, a 600 MWe PWR. The standalone steel structure cost was $2 X$ the steel lined concrete shell cost per unit area due to higher price of procuring and installing steel vs. equivalent steel-lined concrete structures. As such, this analysis accounts for this escalation.

The NuScale containment is more similar to a reactor pressure vessel than a site-built structure. As a result, its cost estimation used Equation 1 for the reactor pressure vessel, but scaled with the mass of the containment. The NuScale containment is stainless steel whereas the PWR12-ME RPV was stainless steel cladded carbon steel, and Towler et al. reported a 2.3X cost escalation for stainless steel vessels over carbon steel vessels. This is the assumed methodology used for this study. It is noted that if the AP1000 stainless steel containment cost is scaled based on its weight and directly applied to NuScale containment, then the cost would be $\sim 10 \%$ lower that the assumed methodology. 


\subsubsection{Design simplifications}

The AP1000, and many subsequent designs, applied substantial simplifications to the reactor plant equipment piping and valve systems. Some of these savings came from improved design, and some came from passive safety features that reduced the number of redundant systems. The EEDB made an estimate of the savings for these simplifications, and we used the APWR6/PWR6 ratio to approximate the savings. Note that the APWR6 was an early conceptual design not identical to the AP600 that ultimately became the AP1000, but these estimated cost savings were taken to be representative of what simplifications were possible from Gen III designs. Table 4 summarizes the relative cost reductions across Account 22 which reports the plant simplifications we applied to the plant models in this study. In contrast to the LPSR, the cost estimate for the LASR did not include cost reductions for account 223 due to non-existence of passive safety systems. However, the cost reductions for the other accounts in Table 4 did apply to LASR based on the available information on APR-1400.

Table 4. APWR6/PWR6 cost ratio for reactor plant equipment design simplification

\begin{tabular}{|c|c|c|c|c|c|}
\hline $\begin{array}{c}\text { Account \& } \\
\text { Description }\end{array}$ & $\begin{array}{c}\text { 222.12: Reactor } \\
\text { Coolant Piping }\end{array}$ & $\begin{array}{c}\text { 223: Safeguards } \\
\text { system }\end{array}$ & $\begin{array}{c}\text { 224: Radwaste } \\
\text { Processing }\end{array}$ & $\begin{array}{c}\text { 225: Fuel Handling } \\
\text { \& Storage }\end{array}$ & $\begin{array}{c}\text { 226: Other Reactor } \\
\text { Equipment }\end{array}$ \\
\hline Ratio & 0.25 & 0.71 & 0.76 & 0.52 & 0.50 \\
\hline
\end{tabular}

The AP1000 had many structural simplifications in Account 21. We used published drawings of the AP1000 plant to estimate the dimensions of each structure for our estimate of the LPSR. The costs were then scaled based on those dimensions and the dimensions of the PWR12 plant. Many buildings were eliminated in the AP1000, for example: emergency feedwater pump building, main steam and feedwater pipe enclosures, and others, and the cost of these buildings were eliminated for the AP1000 model. The APR1400 did not have as many structural simplifications as the AP1000, and this was reflected in the estimate for the LASR.

Similarly, passive safety and digital I\&C should result in dramatic reductions in Account 24: Electrical Plant Equipment. The implemented passive safety eliminated the need for Class 1E emergency diesel generators and certain redundancies, and digital I\&C led to simplified wiring installations. The EEDB made an estimate of these savings for both of these cost reductions - again using the ratio of APWR6/PWR6. Table 5 summarizes the relative cost reductions across account 24 .

Table 5. APWR6/PWR6 cost ratio for electrical plant equipment simplifications from digital I\&C and passive safety.

\begin{tabular}{|c|c|c|c|c|c|}
\hline $\begin{array}{c}\text { Account \& } \\
\text { Description }\end{array}$ & $\begin{array}{c}241: \\
\text { Switchgear }\end{array}$ & $\begin{array}{c}\text { 242: Station Service } \\
\text { Equipment }\end{array}$ & $\begin{array}{c}243: \\
\text { Switchboards }\end{array}$ & $\begin{array}{c}\text { 244: Protective } \\
\text { Equipment }\end{array}$ & $\begin{array}{c}\text { 245: Electrical Structures \& } \\
\text { Wiring Containter }\end{array}$ \\
\hline Ratio & 0.55 & 0.27 & 0.91 & 1.01 & 0.58 \\
\hline
\end{tabular}

NuScale had a further set of cost reductions: no primary coolant pump or piping, integrated pressurizer, and integrated steam generator. The PWR12 steam generator mass was 300 tons total, half of which was the vessel. Ganda scaled steam generator costs by mass [20], so eliminating the steam generator vessel, as in the case of an integral PWR, reduced the steam generator cost by $50 \%$. Similarly, for the pressurizer, as noted by Chen et al. [29], the mass of the pressurizer vessel is the dominant cost relative to the spray nozzle, relief valve, and heater, so the model assumed a $90 \%$ cost reduction. The Electric Power Research Institute has been developing advanced fabrication methods for SMR RPVs that aim to reduce RPV costs by $40 \%$ [30]. Our model assumed that this technology will exist at the time of 
commercialization for NuScale and SMR-160. These assumed cost reductions applied to both the MMNC and the NC-SMR cost estimates and are summarized in Table 6 . The reactor building pool cost for the MMNC scaled using its surface area and the surface area of the spent fuel pool in PWR12-ME.

Table 6. Cost reductions by code of account for integral PWRs

\begin{tabular}{|c|c|c|c|c|c|}
\hline $\begin{array}{c}\text { Account \& } \\
\text { Description }\end{array}$ & $\begin{array}{c}222.11 \text { Primary } \\
\text { coolant pump }\end{array}$ & $\begin{array}{c}222.12 \text { Primary } \\
\text { system piping }\end{array}$ & $\begin{array}{c}222.13 \text { Steam } \\
\text { generators }\end{array}$ & 222.14 Pressurizer & $\begin{array}{c}221.1 \text { Reactor } \\
\text { Pressure Vessel }\end{array}$ \\
\hline Cost Reduction & $100 \%$ & $100 \%$ & $50 \%$ & $90 \%$ & $40 \%$ \\
\hline
\end{tabular}

\subsection{Learning}

By producing a greater number of smaller reactors both factory producers and onsite construction teams learn how to manufacture, construct and install equipment and buildings in a progressively more cost-efficient way. Factory work can be continually refined with no theoretical limit on the cost reduction, so the standard learning rate is modeled as:

Equation 3

$$
\frac{C_{N}}{C_{0}}=N^{\log _{2}(1-r \%)}
$$

Where $C_{N}$ is the cost of the $N$ th component, $C_{0}$ is the cost of the first component, and $r$ is the learning rate. In Equation 3, every time production doubles, the cost has reduced by the fraction $r$. Given the lack of accessible information on learning rates for nuclear plant components, using cost data aggregated by Duffey across gas turbines, wind turbines, small airplanes, and other systems, a least-squares fit of Equation 3 yielded a $16 \%$ learning rate [31]. This cost learning curve applied to the factory costs for new modularized components in our analysis such as the integral reactor primary system of NuScale.

Historical nuclear plant data does not have similarly high and boundless learning. Figure 2a shows cost data from Lovering et al. for the French P4 and the Korean OPR-1000, both of which had a clear asymptotic trend in reductions after the $20 \%$ in total cost reduction [3]. Lovering et al. stated regulatory stability (which was the case for France and ROK) would be key to inferring real learning rates, hence selecting just these two series. Moving from site to site, new workers execute the construction tasks, and while some learning has been retained by the vendor, there is a limit to the value of that learning. Therefore, we hypothesized there would be different learning rates among the factory, labor, and material cost categories.

To divide the learning rate among the factory, labor, and material costs, we used the ratio of direct costs for the PWR12-BE to the PWR12-ME shown in Table 7. Only direct costs are shown here because we address indirect cost estimation in a following section. Table 7 shows Labor hours and cost experienced the greatest cost reduction, followed by Material costs, then Factory costs. Factory cost learning was likely limited as many of these components had already reached substantial production quantities, and thus $N$ in Equation 3 was already very high. Therefore, in our modeling, $N$ started at 100 for Factory costs. Although the data from Duffey indicated no bound for Factory cost reductions, we constrained the Labor and Material cost reductions according to the PWR12-ME to PWR12-BE savings.

Figure $2 \mathrm{~b}$ shows a fit of Equation 3 minimizing the RMS error with different learning rates for factory, labor, and material costs to the average of the OPR-1000 and P4 series data. The Factory cost learning 
rate was $16 \%$ from Duffey, and the fit yielded $13.1 \%$ and $7.1 \%$ learning rates for the Labor and Material costs respectively. As Labor and Material costs are highly correlated, the Labor and Material rates were constrained to reach their thresholds at the same plant number. Table 7 provides a summary of the resulting model used in the remainder of the analysis. These learning rates were inferred from plants that were mostly built at different sites, so the learning rate may be higher for multi-plant sites.

Aggregating the effect across the three learning rates, and assuming no new equipment $\left(\mathrm{N}_{0}=100\right.$ for factory costs), the average learning rate of our model was $7 \%$. These rates were consistent with what others in the field have estimated. Lyons et al. reported a range from 2 to 15\% [32], and a University of Chicago study of nuclear economics reported a range from 3 to $10 \%$ [33].

Our model also accounted for intra-plant learning. For example, in the case of the NuScale plant, there are 12 reactor power modules, so it is unlikely the factory, labor, and material costs will be consistent from fabricating and installing the first to the last module. As a consequence, the learning model in Table 7 accounted for intra-plant multiples. Nevertheless, due to lack of available representative data, the assumed learning is driven from plant level data and applied to individual SSCs. This dilutes the bottom-up nature of our tool and in future work, bottom-up learning models for on-site construction should be developed upon availability of data.

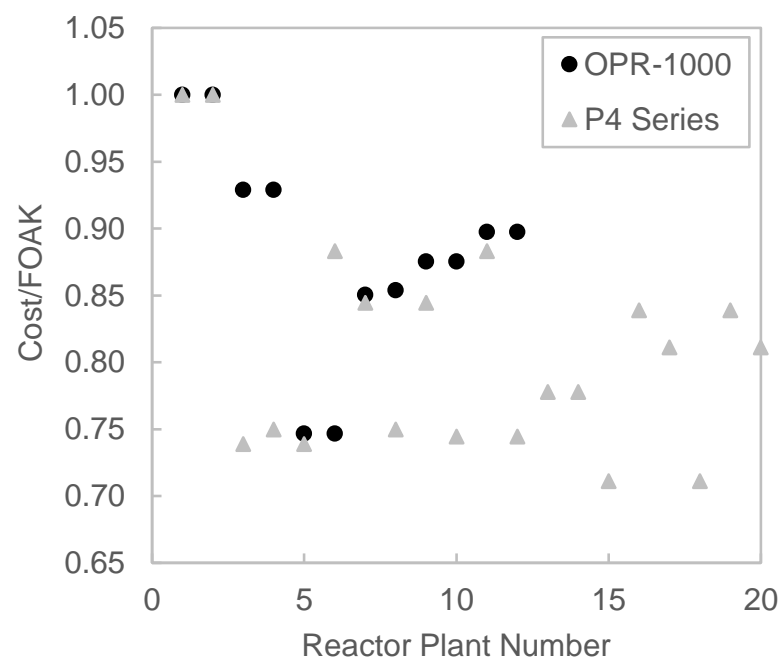

(a)

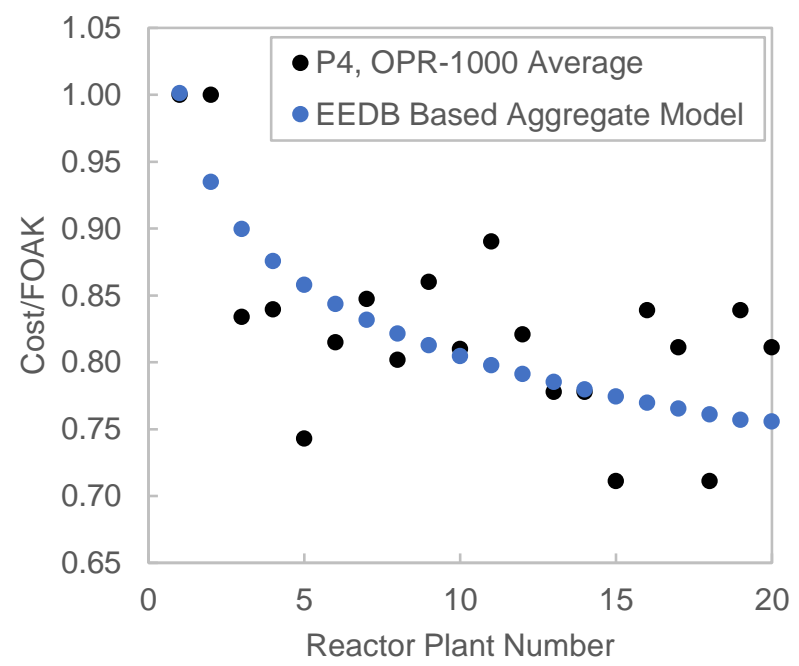

(b)

Figure 2. a) Cost data for the French P4 and Korean OPR-1000 series reactors from Lovering et al. [3]; b) Average of the P4 and $O P R-1000$ costs and the EEDB based learning model aggregating factory, labor, and material cost learning rates and thresholds. The parameters for this model are in Table 7.

Table 7. Ratio of PWR12-BE to PWR-ME direct costs showing the total savings from FOAK to NOAK

\begin{tabular}{|c|c|c|c|c|c|}
\hline & Factory Cost & Labor Hours & Labor Cost & Material Cost & Total Cost \\
\hline$\frac{P W R 12 B E}{P W R 12 M E}$ & $97 \%$ & $55 \%$ & $55 \%$ & $73 \%$ & $76 \%$ \\
\hline $\mathrm{N}_{0}$ & 100 & 1 & 1 & 1 & - \\
\hline Learning rate, $r$ & $16 \%$ & $13.1 \%$ & $13.1 \%$ & $7.1 \%$ & - \\
\hline$C_{N} / C_{0}$ Limit & 0 & $55 \%$ & $55 \%$ & $73 \%$ & - \\
\hline
\end{tabular}

\subsection{Modularity}

Construction time and plant design were two of the IAEA six cost factors, and modularization of SSCs in SMR designs addresses these two factors. SMR designers intend to aggregate subsystems to form 
modules, and modules can be manufactured in a factory, shipped to the site, and installed as a whole. With this construction scheme, modularity reduces the onsite construction labor required for installation. We quantified the impact of this process and integrated it within the EEDB cost scaling framework.

The global consulting firm McKinsey reported that modular construction does not yield significant cost savings, but it does reduce construction time [34]. McKinsey estimated that modular construction reduces onsite labor $25-65 \%$ by shifting $25 \%$ of it offsite and leveraging productivity gains in a factory. The reported site labor savings were clear, but the total cost savings, including construction of the factory to produce the modules, yielded cost changes from $-20 \%$ to $+10 \%$. In this analysis, for modularized accounts, $50 \%$ of labor costs move to factory costs at twice the productivity, reducing the site labor costs and increasing the factory equipment costs. These assumptions were very similar to those recommended by the Economic Modeling Working Group for advanced nuclear reactors [25] and those used by Lyons et al. [32]. In future if data on cost savings from modular construction on individual SSC is available, more granular modular construction model (i.e., bottom-up) could be applied.

For NuScale, the following systems were modular: turbine generator plant equipment, reactor equipment, the main heat transport system, reactor instrumentation and control, and the containment vessel. For SMR-160, the same systems were modularized except the containment vessel.

\subsection{Indirect costs}

The EEDB breaks down indirect costs into three categories: Construction Services, Engineering \& Home Office Services, and Field Supervision \& Field Office Services. We extracted correlations between direct and indirect costs using the data for the PWR12-BE and PWR12-ME. Similar to the direct costs, the EEDB divided the indirect costs into Factory Equipment Cost, Site Labor Hours, Site Labor Cost, and Site Material Cost. Table 8 shows scaling relationships deduced from the reported PWR12-ME and PWR12$\mathrm{BE}$ data that proved to be accurate to $+/-10 \%$. In practice, the direct site labor cost, labor hours, or material cost of the new reactor concept was multiplied by the scaling value to estimate the indirect cost. The indirect material costs were escalated with the ratio of average workers to account for tools and equipment needed for additional workers. The indirect factory costs accounted for home and field offices, taxes, and insurance, so they were escalated with the ratio of construction time as estimated by the vendor.

Table 8. Indirect cost modeling assumptions and relations based on PWR12-ME and PWR12-BE.

\begin{tabular}{|c|c|c|c|}
\hline & Base Scaling Relation & $\begin{array}{c}\text { Base Scaling } \\
\text { Value }\end{array}$ & Escalation Relation \\
\hline Site Labor Cost & $\frac{P W R 12 \text { BE Indirect Site Labor Cost }}{P W R 12 \text { BE Direct Site Labor Cost }}$ & $36 \%$ & - \\
\hline $\begin{array}{c}\text { Site Labor } \\
\text { Hours }\end{array}$ & $\frac{P W R 12 \text { BE Indirect Site Labor Hours }}{P W R 12 \text { BE Direct Site Labor Hours }}$ & $36 \%$ & - \\
\hline $\begin{array}{c}\text { Site Material } \\
\text { Cost }\end{array}$ & $\frac{P W R 12 \text { BE Indirect Site Material Cost }}{P W R 12 \text { BE Direct Site Material Cost }}$ & $79 \%$ & $\frac{\text { New Plant Average \# Workers }}{P W R 12 \text { BE Average \# Workers }}$ \\
\hline $\begin{array}{c}\text { Factory Equip. } \\
\text { Cost }\end{array}$ & $\frac{P W R 12 \text { BE Indirect Factory Cost }}{P W R 12 B E \text { Direct Site Labor Cost }}$ & $132 \%$ & $\frac{\text { New Plant Construction Time }}{P W R 12 \text { BE Construction Time }}$ \\
\hline
\end{tabular}




\section{Results}

\subsection{Benchmarking the model and cost estimates}

In this subsection, the data on total concrete volume and reported cost estimates from the referenced plants (if available) are compared with the developed generic models in this study. For the cost estimates, the vendor and utility estimates that are based on proprietary data on expected overnight cost of the plants are included. In some cases, if the project did not realize unforeseen delays, the final realized cost is also compared. It should be noted that it is generally unclear what is included in the noted cost estimates (e.g. total project cost vs. overnight cost) and the benchmark should be treated as indicative that the model appropriately captures trends but not as model validation.

In scaling the 204 direct SSC costs, the cost estimation tool calculated the total safety grade concrete to make pieces of the cost estimate, and these data are captured in Table 9. The large reactor building in the MMNC plant requires the most safety grade concrete while the NC-SMR required the least. Significant design effort was put into reducing the size and count of safety grade buildings for the LPSR, and as a result, the LPSR had the lowest concrete per MWe capacity required. To benchmark these estimates, Table 9 compares the calculated safety grade concrete to estimates of total concrete from the recent MIT Future of Nuclear study. Assuming safety grade concrete is $60 \%$ of total concrete, the estimates from our mode are within $10 \%$ of the estimates from the MIT Future of Nuclear study.

Table 9. Safety grade concrete for each plant as calculated inside the model compared to an estimate of the total concrete (safety and non-safety) from [1].

\begin{tabular}{|l|c|c|c|c|c|}
\hline & PWR12-ME & LPSR & LASR & MMNC & NC-SMR \\
\hline Safety Grade Concrete $\left(\mathrm{m}^{3}\right)$ & 84,017 & 46,892 & 195,402 & 109,354 & 25,117 \\
\hline Safety Grade Concrete $\left(\mathrm{m}^{3} / \mathrm{MWe}\right)$ & 73 & 42 & 140 & 160 & 157 \\
\hline Total Concrete $\left(\mathrm{m}^{3} / \mathrm{MWe}\right)$ & 122 & 71 & 237 & 229 & 184 \\
\hline Reference Total Concrete (m³/MWe) [1] & $\begin{array}{c}110 \\
\text { (PWR12) }\end{array}$ & $\begin{array}{c}60 \\
\text { (AP1000) }\end{array}$ & - & $\begin{array}{c}260 \\
\text { (NuScale) }\end{array}$ & - \\
\hline
\end{tabular}

The FOAK costs for the reactor concepts are shown in Figure 3a. The FOAK cost estimate for the LPSR was $\$ 4,328 / \mathrm{kWe}$ which was within $1 \%$ of the original cost estimate for the AP1000s at the Vogtle site in the US [2]. However, the realized cost of the Vogtle plant was estimated to be $\$ 8,600 / \mathrm{kWe}$ [2]. Merrow, in a RAND Corporation report that regressed an extensive database of megaprojects, estimated cost escalations of $59 \%$ if a project uses a new construction method and $78 \%$ if a project encounters regulatory challenges [35]. For example, Westinghouse used steel plate composite for constructing the AP1000 shield buildings at the Vogtle site which was the first use of this construction method for nuclear projects in the US. Second, Westinghouse encountered design updates to accommodate regulatory changes around requirements such as for airplane impact to the containment. Both of these factors were likely drivers of the $100 \%$ cost escalation observed at the Vogtle site not accounted for in the current cost model. The AP1000 plants at Sanmen $1 \& 2$ had lower capital costs due to the lower cost of labor and material in China compared to the US. In China, labor rates are 5-18\% of US labor rates [1], and construction commodity prices are up to $25 \%$ lower [36]. Assuming that $30-50 \%$ of factory costs are labor costs for nuclear components [29], with these lower labor and commodity costs in China, the cost model estimates a range of $\$ 1,700-2,300 / \mathrm{kWe}$ for Sanmen 1 \& 2 compared to the initial announced budget of $\$ 2,044 / \mathrm{kWe}[2]$. Also, the cost escalation at Sanmen was less than the escalation at Vogtle, likely because Sanmen did not use steel plate composites or experience as many regulatory hurdles. 
In Table 10, the LASR cost estimates were averaged over the NOAK to fourth-OAK plants because the available costs for the Barakah site in the UAE are from a contract price for four units. The LASR cost estimate was $22 \%$ higher than the realized cost for the four-unit APR1400 plant at Barakah in the UAE. As in the case of Sanmen, however, the lower realized cost is likely the result of lower labor and material costs in the UAE. Dorfman reported KEPCO's bid was about 30\% lower than the next cheapest bid [37] indicating they may have underbid the Barakah site contract to help establish its first international nuclear construction business. Finally, the APR1400 had an advantage over the AP-1000 or EPR in that it was a design evolution from the OPR-1000, and KEPCO had essentially no gap in nuclear construction between the last OPR-1000 and the first APR1400. This is also true for the mentioned positive experience for the Advanced Boiling Water Reactors in Japan.

The MMNC FOAK overnight cost estimate was $\$ 6,554 / \mathrm{kWe}$ which was $37 \%$ higher than the PWR12-ME and 51\% higher than the AP1000. At a meeting for the Carbon Free Power Project for the Utah Associated Municipal Power Systems, a cost estimate of $\$ 6 \mathrm{~B}$ was disclosed [38]. However, this cost is for the total project cost and the overnight cost is only a component of this estimate. Meanwhile, World Nuclear News reported that the NOAK NuScale 720 MWe plant cost is $\$ 3,600 / k W e$ which was within $7 \%$ of our $10^{\text {th }}$-OAK MMNC cost estimate of $\$ 3,856 / \mathrm{kWe}$. Black et al. estimated the overnight capital cost of the NuScale plant to be $\$ 3,466$ which was also near our $10^{\text {th }}$-OAK estimate, but they did not report whether their estimate was FOAK or NOAK. In a relative context, the direct costs between the PWR12 and NuScale were essentially equivalent in their study, whereas we estimated NuScale direct costs to be $60 \%$ higher than the PWR12 direct costs. The primary drivers of these differences were Account 21: Structures and Improvements and Account 23: Turbine Plant Equipment. Account 21 costs for NuScale were more than double than those for PWR12 in our model, consistent with the NuScale plant requiring the most amount of concrete of any nuclear plant concept [1]. The significant low of economy of scale for Account 23 drove NuScale costs much higher than for the PWR12 even accounting for on-site, intraplant learning rates. In summary, while the main motivation behind the development of the cost estimating tool is to derive relative insights into SMR vs. Large LWR cost drivers, the tool still demonstrates its ability to reliably estimate overnight cost of nuclear projects.

Table 10. Capital cost benchmarking between the estimates produced in this work and publicly available dota

\begin{tabular}{|c|c|c|c|}
\hline & $\begin{array}{l}\text { Cost Estimate } \\
(\$ / \mathrm{kWe})\end{array}$ & $\begin{array}{l}\text { Similar reference cost estimates } \\
(\$ / \mathrm{kWe})\end{array}$ & $\begin{array}{l}\text { Similar realized costs } \\
(\$ / \mathrm{kWe})\end{array}$ \\
\hline $\begin{array}{l}\text { Large Passive Safety } \\
\text { PWR (LPSR) }\end{array}$ & $\begin{array}{c}4,328 \\
\text { (FOAK - US) } \\
1,700-2,200 \\
\text { (FOAK - China) }\end{array}$ & $\begin{array}{c}4,300[2] \\
\text { (AP1000 - Vogtle) } \\
2,044[2] \\
\text { (AP1000 - Sanmen) }\end{array}$ & $\begin{array}{c}8,600[2] \\
\text { (Vogtle) } \\
3,154[2] \\
\text { (Sanmen) }\end{array}$ \\
\hline $\begin{array}{l}\text { Large Active Safety } \\
\text { PWR (LASR) }\end{array}$ & $\begin{array}{c}5,337 \\
\text { (First 4-unit average) }\end{array}$ & $\begin{array}{c}4,358 \text { [39] } \\
\text { (APR1400 4-unit average - Barakah) }\end{array}$ & \\
\hline $\begin{array}{l}\text { Multi-module SMR } \\
\text { (MMNC) }\end{array}$ & $\begin{array}{c}3,856 \\
\left(10^{\text {th }}-\text { OAK }\right)\end{array}$ & $\begin{array}{c}3,600[40] \\
\text { (NuScale, NOAK) }\end{array}$ & \\
\hline
\end{tabular}

\subsection{FOAK and $10^{\text {th }}$-OAK Cost Estimates}

Figure 4 breaks down the direct costs for the five reactors into the six accounts from Table 3 . The Structures and Improvements account trends well with the safety grade concrete estimates from Table 9 except for a few cases. The NC-SMR uses less safety grade concrete per unit capacity than the MMNC, and it is only marginally higher than the LASR. This was likely the result of the loss of economy of scale for the small 160 MWe plant - shrinking the building does not allow for the wall and foundation 
thicknesses to shrink because local effects drive the structural design constraints. The LPSR design uses $40 \%$ less safety grade concrete than the PWR12-ME, but the Structures and Improvements account was only $5 \%$ less. This was the result of the expensive passively safe standalone steel containment structure. This type of containment was significantly more expensive than the standard steel lined concrete structure.

Within the Reactor Plant Equipment account, the impact of different design decisions can be seen. In the LPSR, the use of passive safety and a simplified design reduced costs $14 \%$ from the PWR12-ME, but the LASR reduced the cost of this account 5\% from the PWR12-ME with a larger economy of scale. The MMNC had an escalated Reactor Plant Equipment cost due the large number of small-scale vessels, steam generators, and other reactor equipment. The MMNC did benefit from intra-plant learning for the 12 modules. Absent this effect, the MMNC Reactor Plant Equipment costs would have been $21 \%$ higher. Further, the estimate cost reduction by e-beam welding the vessel as proposed by EPRI saved $\$ 279 /$ kWe.

Within Turbine Plant Equipment and Electrical Plant Equipment, there was strong favorability to the large plants over the NC-SMR. In the MMNC plant, each reactor module has its own turbine, so these turbine costs should be high due to the loss of economy of scale. However, intra-plant learning and modularization led to 35\% cost savings for MMNC Turbine Plant Equipment. The passively safe designs, (LPSR, MMNC, and NC-SMR) all benefited from a $43 \%$ cost reduction in Electrical Plant Equipment. The turbine plant equipment cost conclusions should not be treated as universal because a vendor can choose to greatly simplify the turbine equipment by balancing system complexities and thermodynamic efficiencies. For example, the number of feedwater heaters can be reduced resulting in lower system costs but also lower efficiencies. The analysis here assumed a similar level of complexity was maintained as the turbine size was rescaled except in the cases where the turbine plant was modularized. In these cases, the $50 \%$ of site labor costs were shifted to the factory cost consistent with our modularization methodology, and these modules were given higher learning rates.

Figure $2 \mathrm{~b}$ shows learning progression for the overnight costs from the FOAK to the $10^{\text {th }}$-OAK plant for each of the five reactors. The MMNC and NC-SMR, with significant modularization across many categories experienced an average of a $36 \%$ cost reduction. The PWR12-ME, LPSR, and LASR with large structures and heavy dependence on onsite labor experienced a cost reduction of $31 \%$ In absolute numbers, PWR12-ME, LPSR, and LASR experienced roughly $\$ 1,500 / \mathrm{kWe}$ in cost savings across the first ten plants. In contrast, the more heavily modularized plants, MMNC and NC-SMR, experienced roughly $\$ 2,500 / \mathrm{kWe}$ in cost reductions. However, these larger cost reductions did not ultimately result in less expensive plants than either the LPSR or PWR12-ME. 


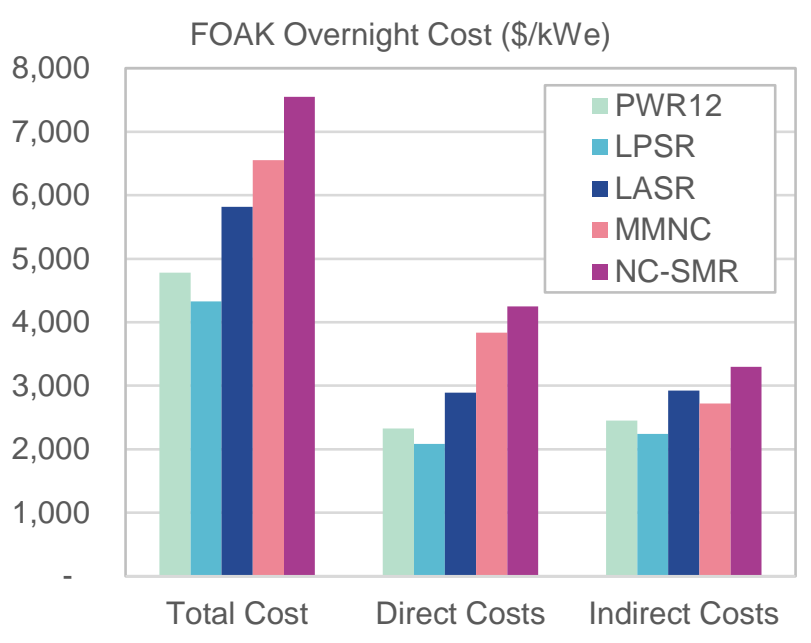

(a)

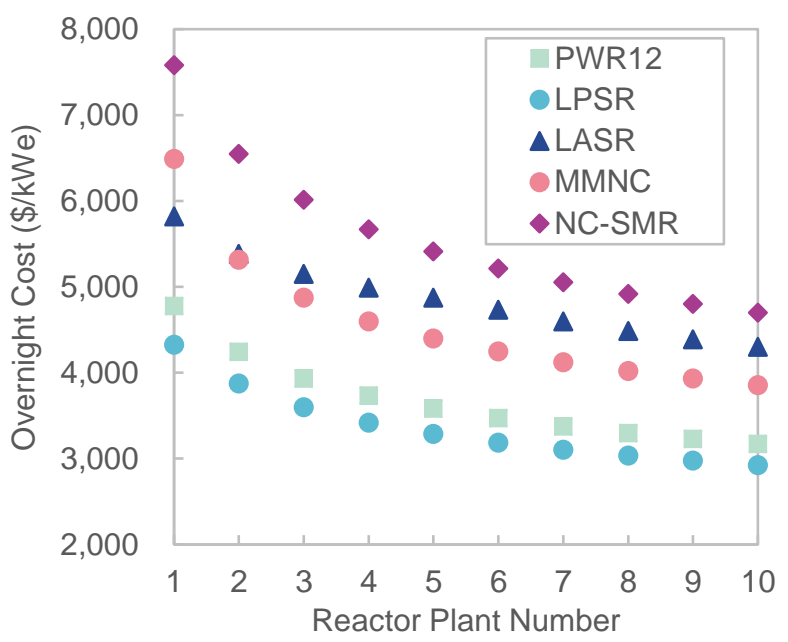

(b)

Figure 3. (a): Total, direct, and indirect cost estimates for the FOAK; (b): Total overnight cost estimates from FOAK to 10th-OAK showing the rate of cost reduction.

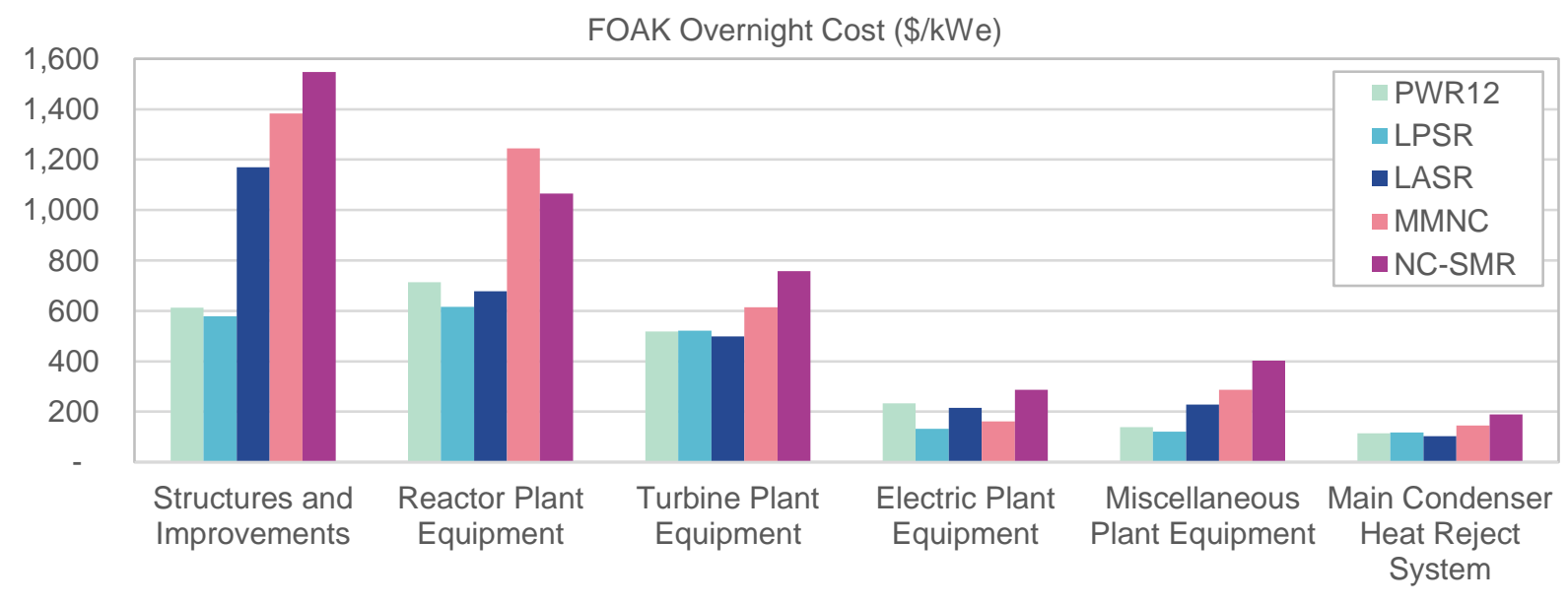

Figure 4. Direct cost estimates broken down into six main accounts.

Passive safety systems in the MMNC plant saved a total of $\$ 398 / \mathrm{kWe}$ : $\$ 125 / \mathrm{kWe}$ in electrical plant equipment, $\$ 68 / \mathrm{kWe}$ in safeguards systems, and $\$ 205 / \mathrm{kWe}$ in associated indirect costs. In comparison, just the liner for the reactor building pool cost $\$ 299 / \mathrm{kWe}$, half direct and half indirect cost. So, the passive safety feature of the MMNC saved in net $\$ 100 / \mathrm{kWe}$ not including the added cost to the reactor building to support the mass of the pool, the cost of the new refueling scheme, or the construction risk associated with such a large civil structure.

The NC-SMR specific costs were the highest among the five plant designs primarily due to the loss of the economy of scale. The exception was that the reactor plant equipment costs were lower for the NC-SMR than for the MMNC because the vessel style containment of the MMNC shifted this cost from structures and improvements to the reactor plant equipment. Despite the high specific cost, the absolute cost of the NC-SMR was only $25 \%$ of the other plants, making it a dramatically smaller construction project.

The LPSR, similar to the AP1000, used steel plate composites for the shield building around the containment. Champlin provided a method for estimating the cost change with steel plate composite 
construction [23]. Steel plate composites replace traditional rebar and formwork for concrete superstructures. The material cost was $1.5 \mathrm{X}$ traditional rebar, but it eliminated formwork cost. There was an added operating engineer cost for using a crane to install the plate composites. For high density rebar, pressure containing structures, steel plate composites should reduce costs, but the LPSR shield building is not a pressure containing structure. As a result, steel plate composites reduced labor costs $\$ 4 / \mathrm{kWe}$ but raised material costs $\$ 9 / \mathrm{kWe}$, for a net increase of $\$ 5 / \mathrm{kWe}$ or about $\$ 5 \mathrm{M}$.

\subsection{Variations on the MMNC Design}

The previous results showed how the cost estimating tool was useful for comparing costs across very different nuclear plant architectures. The cost estimating tool, however, can also estimate the value of different design consideration within a particular architecture. For example, the licensed version of the NuScale plant is a twelve module plant with $160 \mathrm{MWt}$ units, but NuScale has been open about uprating to a twelve module plant with $192 \mathrm{MWt}$ modules, and more recently, NuScale discussed a six and twelve module plants with $246 \mathrm{MWt}$ modules [41]. The aim of each of these iterations is to meet the capacity and cost needs of a particular customer. Here, we evaluated the cost impacts of these proposals on our similar MMNC plant.

For these case studies, the number of modules affected the number of vessels, steam generators, control rods, turbines etc., but the size of the reactor building and pool were constant. The number of reactors and their thermal power affected the coolant flow rate through the core which in turn affected the cost of the nuclear service water system, liquid waste system, and gas waste system. The plants with lower number of modules accrued learning by doing savings more slowly. For the original MMNC plant, the turbine building was in two parts with six turbines each, so for the six module plants, one turbine building was eliminated. The overnight costs were estimated for four cases shown in Figure 5 and Figure 6.

These four cases showed an interesting balance of the economy of scale and total project cost. The first uprate from $12 \times 160 \mathrm{MWt}$ to $12 \times 192 \mathrm{MWt}$, lowered the cost-per-unit-capacity cost $14 \%$ while only increasing the total plant cost 4\%. Downsizing from $12 \times 192 \mathrm{MWt}$ to $6 \times 192 \mathrm{MWt}$ lowered the total plant cost $29 \%$ but raised the cost-per-unit-capacity $43 \%$. Scaling the reactor building and pool down to match the six module plant yielded an additional $6 \%$ in cost reductions.

Similar to the first uprate, going from 6 × $192 \mathrm{MWt}$ to 6 × $246 \mathrm{MWt}$ lowered the cost-per-unit-capacity $19 \%$ while only increasing the total plant cost by $4 \%$. In the first two cases, the Structures \& Improvements cost was identical, and the difference seen in Figure 6 was due to the plant capacity change. Within the Reactor Plant Equipment cost account, the twelve $160 \mathrm{MWt}$ module plant and six $246 \mathrm{MWt}$ module plants had similar costs - showing an equilibrium point of learning (twelve module plant) and power uprate (six module plant). These tradeoffs can help reactor designers and utilities make more informed decisions, and this opens the door for automated design optimization for lowest cost and/or best market capacity fit. 


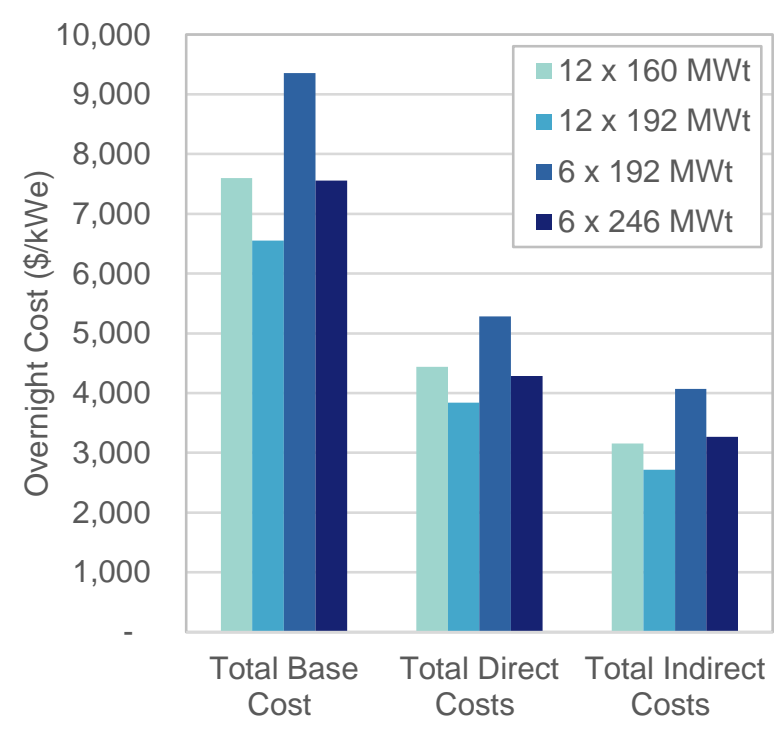

Figure 5.FOAK overnight costs normalized to the plant capacity for four iterations of the MMNC plant;

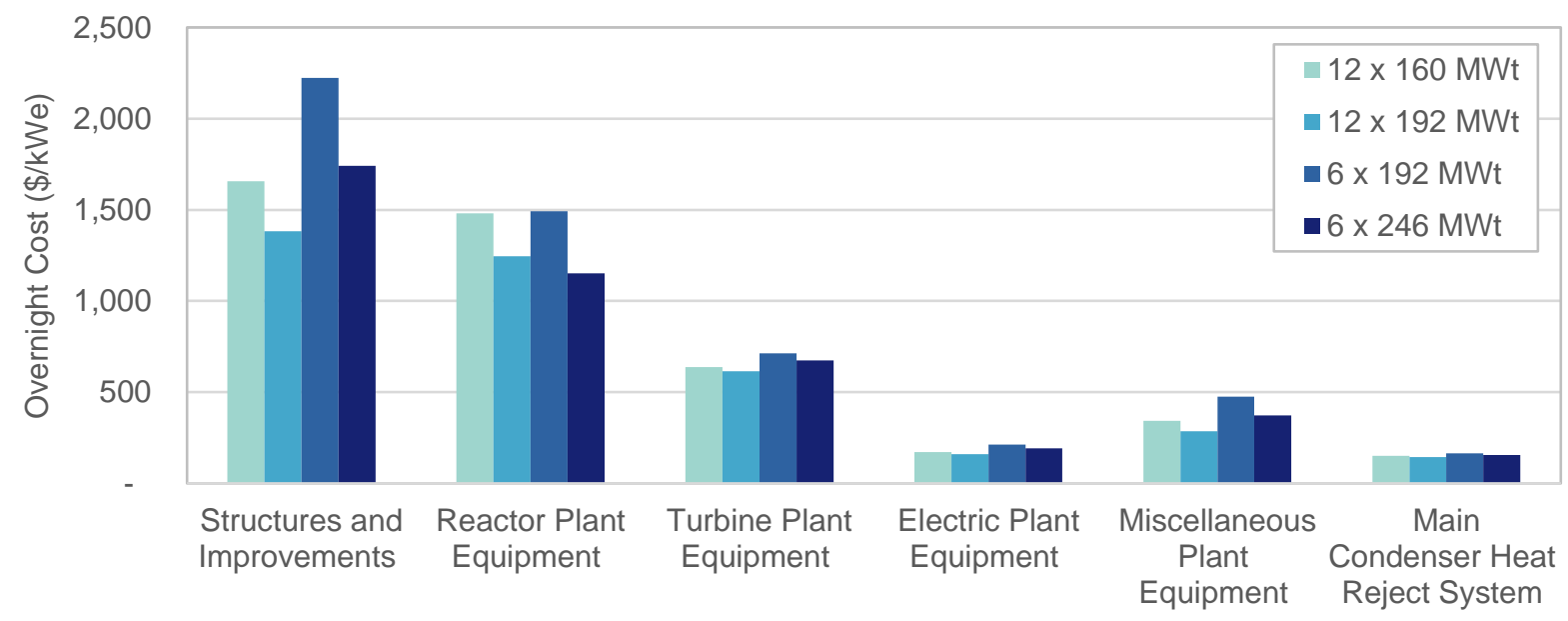

Figure 6. FOAK overnight costs normalized to the plant capacity for four iterations of the MMNC plant for six cost categories.

\section{Discussion}

The remaining factor in the IAEA's list, is "Unit Timing" which accounts for the ability of smaller nuclear plants to cumulatively meet demand and lower the total capital at risk during construction. While Figure $2 \mathrm{~b}$ showed the savings from the first unit to the tenth unit, that representation did not account for the capacity of each unit. Thus, Figure 7 charts the cumulative costs versus cumulative installed capacity. In Figure 6, the result of the cumulative cost analysis showed the LPSR was the lowest cost option, consistent with the previous results, unless less than $1 \mathrm{GWe}$ of total capacity is required. The smaller size and learning rates allow for five NC-SMR plants to be built for the cost of the first LPSR plant. Similarly, four NC-SMR plants can be built for less than the cost of the first MMNC plant. Even though the FOAK NC-SMR plant was $20 \%$ higher cost per unit capacity than the MMNC, the cumulative costs track in line in Figure 7. The LASR plant had a similar trend, where two MMNC plants or nine NC-SMRs cost the same as one LASR. Further, the slow learning rate of the onsite labor heavy LASR design allowed 
for both the NC-SMR and MMNC to have lower equivalent capacity cumulative costs after the second LASR plant.

Carelli et al. showed smaller units such as the NC-SMR have lower total capital invested in any one year and bring in revenue streams more quickly due to their shorter deployment schedules. As a result, they will accumulate less interest during construction which will lower total capital costs, and they may attract lower cost capital via lower interest rates.

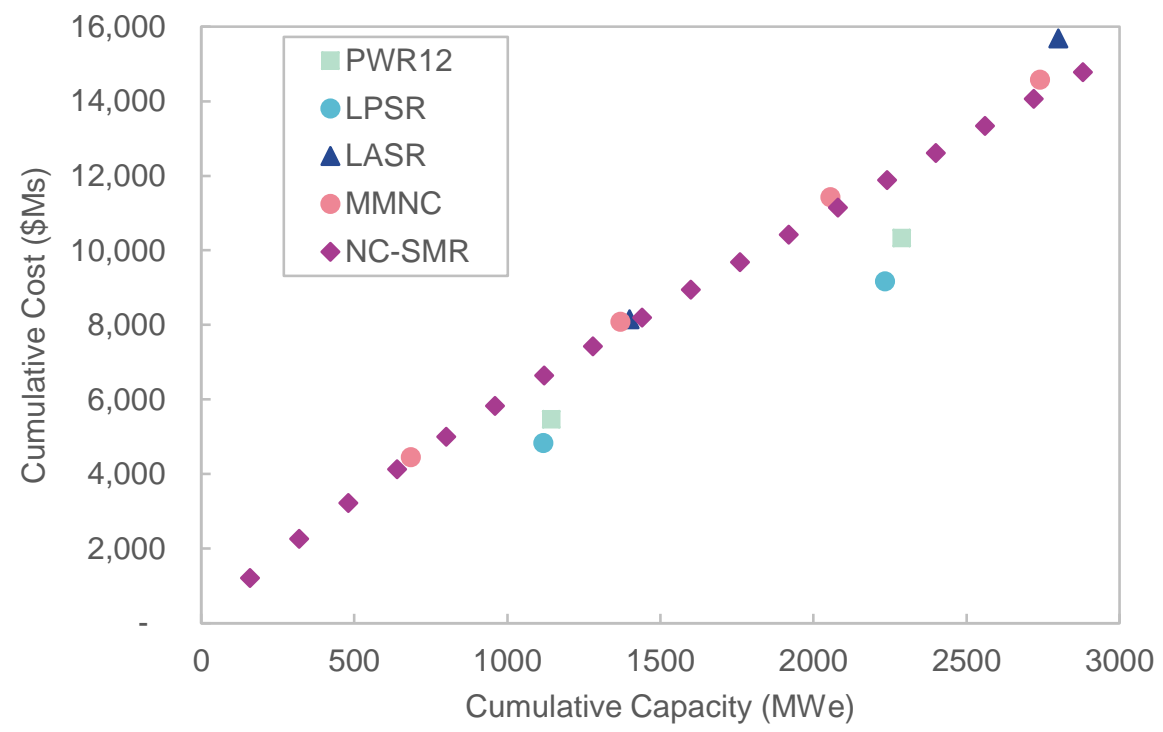

Figure 7. Cumulative costs for consecutive deployments of each reactor type. Each point is a new plant.

The cumulative capacity and cost trends also have risk-informed decision making implications. Although difficult to quantify, megaprojects, which most nuclear projects are, are at a high risk of cost overruns and delays. Many have studied this field, and there is disagreement as to the extent that project characteristics or stakeholder's perspective drives the cost overruns associated with megaprojects [44]. However, in evaluating the megaproject-cost overrun risk associated with a particular nuclear design, we focused on the design centric project characteristics because at this stage of analysis, these are observable. Other factors such as optimism bias, stakeholder conflict, organizational complexity, etc. are all strong cost overrun drivers [44] but cannot be evaluated at the conceptual design phase of a nuclear plant. Further, some project characteristics are inherent to any nuclear project: interdependent systems, multi-disciplinary teams, high degree of regulation. We do not discuss these aspects as they are not differentiable among nuclear projects. A survey of the literature ( [45] [46] [47] [48] [35]), led to four key factors that were correlated with cost escalations and construction delays: projects with total installed cost greater than $\$ 1.5 \mathrm{~B}$, use of a new construction method, a long construction duration, a low use of offsite labor. We translated these factors into a qualitative assessment of the five reactor designs considered in this paper in Table 11.

Except for the NC-SMR, all designs had FOAK costs greater than $\$ 1.5 \mathrm{~B}$. Both the MMNC and LPSR proposed using steel plate composites which is still a new construction method in the nuclear industry. Onsite direct labor hours were high for all designs except the NC-SMR. 5.2 million person-hours of work was still a large size project, but it was less than one third any of the other plants. The LASR had the highest number of onsite labor hours required with over 35 million hours. In practice this design 
architecture can work in low labor cost or high labor efficiency environments such as China and Korea. In the US and the EU, however, high labor costs make this prohibitively expensive. Both MMNC and NCSMR used modularization to shift $29 \%$ and $22 \%$ of onsite labor to offsite facilities, respectively. After considering modularization, however, MMNC and NC-SMR both still required substantially more onsite labor per plant capacity (hours/kWe) than the PWR12 or LPSR. This result revealed SMR plants are not necessarily more factory produced than traditional large PWRs.

The NC-SMR was the superior design from a cumulative cost and megaproject-risk perspective for markets with less than $3 \mathrm{GWe}$ of demand. However, if the plant is entering a large market with a high probability of more than 3 GWe installed capacity, the LPSR, despite the megaproject risks, potentially becomes the better option.

Table 11. Factors correlated to megaproject cost overruns and construction delays [46] [47] [48] [35]. Note: For NC-SMR Nth-ofa-Kind $\left(20^{\text {th }}\right.$ order) numbers are also included in brackets.

\begin{tabular}{|l|c|c|c|c|c|}
\hline Factor & PWR12 & LPSR & LASR & MMNC & NC-SMR \\
\hline FOAK >\$1.5B & $\checkmark$ & $\checkmark$ & $\checkmark$ & $\checkmark$ & - \\
\hline New construction method & - & $\checkmark$ & - & $\checkmark$ & $\checkmark$ \\
\hline $\begin{array}{l}\text { Long construction duration } \\
\text { (FOAK direct onsite } \\
\text { person-hours) } \\
\text { (Hours/kWe) }\end{array}$ & $\begin{array}{c}\checkmark \\
(21.9 \text { Million) } \\
(19.1)\end{array}$ & $\begin{array}{c}\checkmark \\
(17.7 \text { Million) } \\
(15.8)\end{array}$ & $\begin{array}{c}\text { (36.3 Million) } \\
(25.9)\end{array}$ & $\begin{array}{c}\text { (17 Million) } \\
(24.8)\end{array}$ & $\begin{array}{c}(5.2[2.9] \text { Million) } \\
(33[18])\end{array}$ \\
\hline $\begin{array}{l}\text { Low \% Modularized } \\
\text { (\% Total labor moved } \\
\text { offsite) }\end{array}$ & $\checkmark$ & $\checkmark$ & $\checkmark$ & & $(29 \%)$ \\
\hline
\end{tabular}

\section{Conclusions and Future Work}

This work presented a bottom-up advanced nuclear power plant cost estimation tool. The tool has value as an independent analysis of vendor quotes useful for policymakers, utilities, and designers. As a demonstration of the methodology, we estimated the costs for the first ten plants from FOAK to NOAK for five reactor designs: a Gen III PWR - PWR12, a large passive safety PWR - LPSR, a large active safety reactor - LASR, a multi-module natural convection SMR - MMNC, and a natural convection SMR - NCSMR. The LPSR was the lowest cost per capacity plant but was at high risk for cost overruns and delays as a megaproject. The NC-SMR was the most expensive FOAK per unit capacity but had equal or better cumulative costs per cumulative capacity to the LASR and MMNC plants, and the lowest risk for cost overruns. This demonstrated that learning-by-doing is the best cost reducing strategy for new nuclear projects, and smaller plants, that are highly modularized, can most effectively leverage this strategy. Modularization alone is not a sufficient cost reducing strategy, but it augments the impact of learningby-doing.

All of the cost differences estimated here can be eclipsed by cost overruns and delays. In considering the megaproject cost overrun drivers, the best option for lowest cost and risk is to optimize the design using traditional construction methods where there is ample supply of nuclear specific skilled labor such as the LASR (e.g. APR1400) experience. This strategy avoids the potential cost overruns and delays associated with new construction techniques and is likely to achieve NOAK costs more quickly.

While the methodology presented here was fairly comprehensive, there were many assumptions and uncertainties. The learning and modularization models that were applied on the individual SSCs were derived based on high level data and exploring a bottom-up methodology in their treatment is 
worthwhile. Future work should also include uncertainty quantification of the learning, modularization, and indirect cost estimation models. Maronati et al. assessed the cost of unknown unknowns in nuclear plant construction for the generic PWR12 design [49]. Future work should attempt to quantify the megaproject risk and unknown unknowns for specific nuclear plant designs, so that the analyses that were performed to create Figure $2 b$ and Figure 7 can be corrected to account for these risks. This proposed analysis will need to include some assessment of the uncertainty associated with these risks as well. Finally, detailed O\&M cost estimation and cost reduction strategies to overcome lack of economy of scale should not be ignored and will be included in the overall costing methodology. In this future state, the model can be used as an active part of the design process for optimization and optimization under uncertainty.

\section{Acknowledgments}

This work was primary support by Electricite de France (EDF) and partially supported by FORTUM. The authors thank the EDF project advisory board including Prof. Jacopo Buongiorno (MIT), Mr. Eric Ingersoll (LucidCatalyst and Terrapraxis), Dr. Jeremy Gregory (MIT) and Prof. Keith Ridgway (University of Strathclyde). The review comments by Prof. Bojan Petrovic and Dr. Romney Duffey were also appreciated.

\section{Credit author statement}

W. Robb Stewart: Methodology, Software, Formal Analysis, Visualization, Investigation, Writing - Original Draft

Koroush Shirvan: Conceptualization, Methodology, Investigation, Supervision, Funding acquisition, Writing - Original Draft

\section{References}

[1] J. Buongiorno and e. al., "The Future of Nuclear Energy in a Carbon Constrained World," MIT Energy Initiative, Cambridge, 2018.

[2] Nuclear Energy Agency, "Unlocking Reductions in the Construction Costs of Nuclear: A Practical Guide for Stakeholders," OECD, 2020.

[3] J. R. Lovering, A. Yip and T. Nordhaus, "Historical construction costs of global nuclear power reactors," vol. 91, 2016.

[4] M. D. Carelli, P. Garrone, G. Locatelli, M. Mancini, C. Mycoff, P. Trucco and M. E. Ricotti, "Economic features of integral, modular, small-to-medium size reactors," Progress in Nuclear Energy, vol. 52, no. 4, pp. 403-414, 52010. 
[5] V. Kuznetsov, "Options for small and medium sized reactors (SMRs) to overcome loss of economies of scale and incorporate increased proliferation resistance and energy security," Progress in Nuclear Energy, vol. 50, no. 2-6, pp. 242-250, 2008.

[6] M. V. Ramana, "Small Modular and Advanced Nuclear Reactors: A Reality Check," IEEE Access, vol. 9, pp. 42090-42099, 2021.

[7] B. K. Sovacool and M. V. Ramana, "Back to the Future: Small Modular Reactors, Nuclear Fantasies, and Symbolic Convergence," Science, Technology, and Human Values, vol. 40, no. 1, pp. 96-125, 7 2014.

[8] International Atomic Energy Agency Department of Nuclear Energy, "Advances in Small Modular Reactor Technology Developments," Austria, 2020.

[9] B. Mignacca and G. Locatelli, "Economics and finance of Small Modular Reactors: A systematic review and research agenda," Renewable and Sustainable Energy Reviews, vol. 118, 2020.

[10] Black \& Veatch, "Cost and Performance Data for Power Generation Technologies," National Renewable Energy Laboratory, 2012.

[11] P. Scherrer, "Estimating the cost of Small Modular Reactors," Grenoble Phelma, Grenoble, France, 2017.

[12] G. Black, F. Aydogan and C. Koerner, "Economic viability of light water small modular nuclear reactors: General methodolgy and vendor data," vol. 103, 2019.

[13] Ux Consulting, "SMR Market Outlook," Roswell, GA, 2013.

[14] R. Rosner, S. Goldberg and J. S. Hezir, "Small Modular Reactors-Key to Future Nuclear Power Generation in the," 2011.

[15] Z. Zhang and Y. Sun, "Economic potential of modular reactor nuclear power plants based on the Chinese HTR-PM project," Nuclear Engineering and Design, vol. 237, no. 23, pp. 2265-2274, 12 2007.

[16] G. Maronati, B. Petrovic and P. Ferroni, "Assessing I2S-LWR economic competitiveness using systematic differential capital cost evaluation methodology," Annals of Nuclear Energy, vol. 145, 2020.

[17] C. A. Lloyd, T. Roulstone and R. E. Lyons, "Transport, constructability, and economic advantages of SMR modularization," Progress in Nuclear Energy, vol. 134, 42021.

[18] International Atomic Energy Agency, "Approaches for Assessing the Economic Competitiveness of Small and Medium Sized Reactors," IAEA Nuclear Energy Series, Vienna, 2013.

[19] U.S. DOE, "Phase IX Update (1987) Report for the Energy Economic Data Base Program," U.S. Department of Energy, 1988. 
[20] F. Ganda, T. Taiwo and T. Kim, "Report on the Update of Fuel Cycle Cost Algorithms," Argonne National Laboratory, Chicago, 2018.

[21] F. Ganda, E. Hoffman, T. Taiwo, T. Kim and J. Hansen, "Report on the ACCERT Cost Algorithms Tool," Argonne National Lab, Chicago, 2019.

[22] Energy Impact Center, "OPEN100 Economics," [Online]. Available: https://www.open100.com/economics. [Accessed 1311 2020].

[23] P. Champlin, "Techno-Economic Evaluation of Cross-Cutting Technologies for Cost Reduction in Nuclear Power Plants," MIT. Masters Thesis, 2018.

[24] G. Towler and R. Sinnott, "Chapter 7 - Capital Cost Estimating," in Chemical Engineering Design (Second Edition), Butterworth-Heinemann, 2013, pp. 307-354.

[25] The Economic Modeling Working Group of the Generation IV International Forum, "Cost Estimating Guidelines for Generation IV Nuclear Energy Systems," OECD Nuclear Energy Agency, 2007.

[26] BLS, "Occupational Employment Statistics," U.S. Department of Labor, Bureau of Labor Statistics, Washington, D.C., 2019.

[27] W. Vatavuk, "Updating the CE Plant Cost Index," Chemical Engineering, pp. 62-70, January 2002.

[28] EPRI, "Workshop about Economics-Based R\&D for Nuclear Power Construction," 2019.

[29] X. Chen, A. Kotlyarevsky, A. Kumiega, J. Terry, B. Wu, S. Goldberg and E. A. Hoffman, "Small Modular Nuclear Reactors: Parametric Modeling of Integrated Reactor Vessel Manufacturing Within a Factory Environment," U.S. Department of Energy , 2013.

[30] D. Gandy and M. Albert, "SMR Pressure Vessel Manufacturing and Fabrication," Electric Power Research Institute, 2019.

[31] R. Duffey, "Size and Cost Optimization of Nuclear Reactors in Energy Markets: The Need for New Approaches and Advances," Ottawa, 2018.

[32] R. Lyons and T. Roulstone, "Production Learning in a Small Modular Reactor Supply Chain," The International Congress on Advances in Nuclear Power Plants, 2018.

[33] G. S. Tolley and D. W. Jones, "The Economic Future of Nuclear Power," The University of Chicago, 2004.

[34] N. Bertram, S. Fuchs, J. Mischke, R. Palter, G. Strube and J. Woetzel, "Modular construction: From projects to products," McKinsey \& Company: Capital Projects \& Infrastructure, 2019.

[35] E. Merrow, "Understanding the Outcomes of Megaprojects," RAND Corporation, 1984. 
[36] SteelBenchmarker, "Global HRB Prices Sustain Prolonged Rally," www.steelbenchmarker.com, 2020.

[37] P. Dorfman, "Gulf Nuclear Ambition: New Reactors in United Arab Emirates," The Nuclear Consulting Group, 2019.

[38] Utah Associated Municipal Power Systems (UAMPS), "Development Approach to the Carbon Free Power Project," 21 July 2020. [Online]. Available:

https://www.losalamosnm.us/UserFiles/Servers/Server_6435726/File/Government/Departments/ Public\%20Utilities/CFPP/20200721-

Presentations/CFPP\%20Town\%20Hall\%20Development\%20Approach\%20_Mason\%20Baker_7-2120.pdf.

[39] Nuclear Engineering International, "Kepco and Enec set up joint venture for Barakah NPP," 25 October 2016. [Online]. Available: https://www.neimagazine.com/news/newskepco-and-enec-setup-joint-venture-for-barakah-npp-5647366/. [Accessed 18 November 2020].

[40] World Nuclear News, "NuScale announces SMR power uprate," 11 November 2020. [Online]. Available: https://www.world-nuclear-news.org/Articles/NuScale-announces-SMR-poweruprate\#: :text=The\%20increase\%20in\%20generating\%20capacity,about\%20USD2850\%2C\%20the \%20company\%20said. [Accessed 912 2020].

[41] NuScale Power, "NuScale Power Announces an Additional 25 Percent Increase in NuScale Power Module $^{\mathrm{TM}}$ Output; Additional Power Plant Solutions," 2020. [Online]. Available: https://newsroom.nuscalepower.com/press-releases/news-details/2020/NuScale-PowerAnnounces-an-Additional-25-Percent-Increase-in-NuScale-Power-Module-Output-AdditionalPower-Plant-Solutions/default.aspx.

[42] C. Lewis, R. MacSweeney, M. Kirschel, W. Josten, T. Roulstone and G. Locatelli, "Small modular reactors Can building nuclear power become more cost-effective?," Ernst \& Young Global Limited, London, 2016.

[43] G. Black and S. Peterson, "Economic Impact Report: Construction and Operation of a Small Modular Reactor Electric Power Generation Facility at the Idaho National Laboratory Site, Butte County, Idaho," Regional Economic Development for East Idaho, 2019.

[44] G. Locatelli, "Why are Megaprojects, Including Nuclear Power Plants, Delivered Overbudget and Late? Reasons and Remedies," 2018.

[45] G. Locatelli, M. Mikic, M. Kovacevic, N. Brookes and N. Ivanisevic, "The Successful Delivery of Megaprojects: A Novel Research Method:," https://doi.org/10.1177/875697281704800506, vol. 48, no. 5, pp. 78-94, 102017.

[46] A. Fayek, S. Revay, D. Rowan and D. Mousseau, "Assessing Performance Trends on Industrial Construction Mega Projects," Cost Engineering, vol. 48, pp. 16-21, 2006. 
[47] A. Chanmeka, S. Thomas, C. Caldas and S. Mulva, "Assessing key factors impacting the performance of oil and gas projects in Alberta," Can. Journal of Civl Engineering, vol. 39, pp. 259270, 2012.

[48] B. Flyvbjerg, "What You Shoul Know About Megaprojects and Why: An Overview," Project Management Journal, pp. 6-19, 2014.

[49] G. Maronati and B. Petrovic, "Making Construction Cost Estimate of Nuclear Power Plants Credible: Assessing Impact of Unknown Unknowns," Nuclear Technology, 2020.

[50] C. Lloyd, C. Middleton and T. Roulstone, "The impact of modularisation strategies on Small Modular Reactor Costs," The International Congress on Advances in Nuclear Power Plants, 2018. 